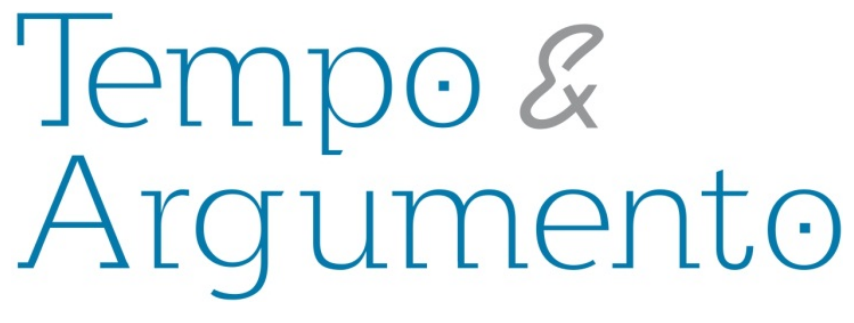

\title{
Ditaduras civil-militares no Cone Sul e a Doutrina de Segurança Nacional - algumas considerações sobre a Historiografia
}

\begin{abstract}
Resumo
Os anos de 2013 e 2014 são significativamente relevantes para se refletir sobre as ditaduras civil-militares estabelecidas no Cone Sul. Em 2013 completam-se os trinta anos da saída dos militares no governo da Argentina e os quarenta anos do movimento que derrubou o governo democraticamente eleito de Salvador Allende. Por sua vez, no ano de 2014 se completará o cinquentenário da tomada do poder capitaneada pelos militares. Nesse sentido, entendo ser relevante uma abordagem que avalie as primeiras obras acerca do conjunto de ideias que norteou essas ditaduras - a Doutrina de Segurança Nacional. Elaboradas entre os anos de 1979 e 1982, referem-se a um primeiro esforço de análise sobre o autoritarismo que atingiu Argentina, Brasil, Chile e Uruguai.
\end{abstract}

Palavras-chave: Doutrina de Segurança Nacional. Ditaduras. Cone Sul.

\section{Ricardo Antonio Souza Mendes}

Doutor em História pela

Universidade Federal Fluminense (UFF). Professor Adjunto de História das Américas no Instituto de

Filosofia e Ciências Humanas da Universidade do Estado do Rio de Janeiro (UERJ). rasmric@oi.com.br

\section{Para citar este artigo:}

MENDES, Ricardo Antonio Souza. Ditaduras civil-militares no Cone Sul e a Doutrina de Segurança

Nacional - algumas considerações sobre a Historiografia. Revista Tempo e Argumento,

Florianópolis, v. 5, n.10, jul./dez. 2013. p. 06 - 38. 


\title{
Civil-military dictatorships in the Southern Cone and the National \\ Security Doctrine - some considerations on the historiography
}

\begin{abstract}
The years 2013 and 2014 are especially relevant to reflect on the civil-military dictatorship established in the Southern Cone. 2013 marks the 30 year anniversary of end of the military government in Argentina and the 40 year anniversary of the movement which overthrew the democratically elected President Salvador Allende. Thus the year 2014 will mark the 50th anniversary of the coup perpetrated by the military (where?). In this sense, I believe it is important to address the first written works containing the ideas that set the basis for those dictatorships: the National Security Doctrine. Produced between 1979 and 1982, they refer to a first effort of analysis on the authoritarianism that hit Argentina, Brazil, Chile and Uruguay.
\end{abstract}

Keywords: National Securyti Doctrine. Dictatorships. Southern Cone.

\section{Introdução}

Nas décadas de 1960 e 1970 observa-se uma profunda acentuação da mobilização dos movimentos sociais na América Latina que reivindicavam, no plano político, a ampliação do direito de voto e o aperfeiçoamento do sistema democrático com o efetivo reconhecimento de novos atores sociais. No plano econômico-social, ambicionavam uma melhor distribuição da propriedade da terra e da riqueza produzida em suas nações, a ampliação e disseminação de direitos 
trabalhistas para o conjunto da classe trabalhadora rural, assim como outras reivindicações mais que possibilitassem melhorar suas condições de vida.

Nessa conjuntura, o efeito da ocorrência da Revolução Cubana de 1959 adquiriu um papel de destaque no Continente. Após mais de três anos de luta contra o governo de Fulgêncio Batista, apoiado pelos Estados Unidos, segmentos oriundos das camadas médias organizadas em torno do Movimento 26 de Julho (M-26-07) lideraram uma ampla frente de oposição armada contra a ditadura. Diversos setores das camadas menos abastadas da sociedade cubana apoiaram o movimento que, após a sua chegada ao poder, empreendeu uma série de reformas que alteraram profundamente o nível de distribuição da riqueza no país e proporcionaram ganhos expressivos para essa parcela da sociedade. Em um contexto mundial de intenso processo de descolonização, a Revolução Cubana parecia indicar que também na América Latina colocava-se a possibilidade de profundas alterações na ordem social vigente.

Como parte dessa situação, a partir de 1964 se desenvolveu, inicialmente, no Cone Sul e posteriormente em boa parte da América Latina, a proliferação de ditaduras que adotaram a Doutrina de Segurança Nacional (DSN) como referência para a compreensão da realidade com a qual se deparavam. O pioneirismo no estabelecimento dessas ditaduras civil-militares coube ao Brasil, que deu o pontapé inicial do que foi uma verdadeira onda de regimes cerceadores da limitada participação política presente naquele momento. Argentina (1966 e novamente em 1976), Chile (1973), e Uruguai (1976) sucederam o caso brasileiro. Na sequência, a quase totalidade dos países da região foi submetida a regimes autoritários, em maior ou menor grau influenciados pela DSN, com exceção de Venezuela e México.

Apesar de capitaneadas por membros das Forças Armadas, em todas essas nações os militares lideraram uma coalizão composta também por membros oriundos da sociedade civil e apoiada por partidos políticos das direitas no Brasil (MENDES, 2003, p. 4), Argentina (SURIANO, 2005, p. 15), Chile (YOCELEVSKY, 2002, p. 92-103) e Uruguai (PADRÓS, 2004, p.54.) '.Contudo, inquestionavelmente a liderança das Forças Armadas deu o tom do período. Uma vez consolidada

\footnotetext{
${ }^{1}$ Como exemplos da intensa participação de grupos da sociedade civil podemos citar os casos chileno e brasileiro. No primeiro, observa-se o apoio do Partido Nacional bem como de instituições do empresariado, tais como o Instituto de Estudios Generales, dentre outros. No caso brasileiro a colaboração do Instituto de Pesquisas e Estudos Sociais (IPÊS) e de partidos como a União Democrática Nacional (UDN) são notórias. Em ambos os casos, as Forças Armadas utilizaram-se de quadros fornecidos por estas instituições para governar. Além disso, não se pode esquercer que nos dois casos observa-se a disseminação da DSN pela elite civil através de um trabalho de propaganda realizado por escritores, intelectuais e jornalistas.
} 
No Brasil, o estabelecimento da ditadura de Segurança Nacional consolidou-se de fato em 1968, sendo estruturada gradativamente após o movimento civil-militar ter colocado os militares no poder em 1964. Ainda assim, desde seu início, ocorria uma intensa repressão no país com a proliferação gradual, mas contínua, da tortura enquanto instrumento das atividades de inteligência e segurança (FICO, 2003, p. 181). Desencadeou-se uma gigantesca depuração na vida política de forma a instaurar um arremedo de vida democrática, com eleições dentre aqueles que faziam parte de uma oposição tolerada pelo regime. Após o Al-5, contudo, cresceram as cassações e perseguições políticas, desencadeando-se uma intensa centralização do poder nas mãos do executivo, com o respectivo esvaziamento do legislativo e judiciário. A implantação da Lei de Segurança Nacional significou a efetiva implementação da DSN no Brasil, autorizando a intervenção do governo em "qualquer nível de atividade social se julgasse que a segurança nacional havia sido violada" (SKIDMORE, 1988, 219). A partir daí ampliou-se o número de pessoas que seriam enquadradas como opositores do regime (MORAES, 2004, p. 304) ${ }^{2}$. A tortura tornouse um recurso de controle social, "um poderoso instrumento, ainda que degradante para seus usuários, para subjugar a sociedade” (SKIDMORE, 1988, p. 181).

Por sua vez, no Chile, a chegada ao poder dos militares com ampla colaboração da elite política e empresarial civil, derrubou Salvador Allende no fatídico 11 de setembro de 1973. Dois anos depois se iniciou um processo de afastamento das elites políticoempresariais da estrutura de poder. O Estado se tornou cada vez mais militarizado. Todas as instâncias administrativas passaram a ser ocupadas por membros das forças armadas e policiais: governos de províncias, prefeituras, postos de chefia das diversas empresas nacionais e até mesmo os presidentes de associação de bairros. Em 1977 todos os partidos políticos foram dissolvidos. O único espaço que continuou fora do alcance dos militares foi o comando da economia, destinado aos seguidores da Escola de Chicago. A repressão aos opositores no Chile alcançou índices de depuração política,não vistos na América Latina até então. Milhares de vítimas, incluindo cerca de dois mil membros das próprias Forças Armadas foram eliminados (ROUQUIÉ, 1984, p. 305). Cerca de um por cento da população chilena foi detida somente no primeiro ano do novo governo.

\footnotetext{
${ }^{2}$ A autora cita como sinal da desmedida repressão a denominada "Operação Tarrafa", desencadeada pelo Estado Maior do II Exército e destinada a identificar e prender opositores do regime mesmo que não representassem ameaça aparente.
} 
O cerceamento da vida democrática no Uruguai iniciou-se, ainda, ao longo do governo civil do Colorado Pacheco Areco, em 1968, e acabou por completar-se cinco anos depois na Presidência de Juan Maria Borbaderry. Diferentemente do caso chileno, o principal recurso para atemorizar a oposição não foi a eliminação física, mas o encarceramento massivo e o sequestro realizado por membros das Forças Armadas, gerando o que Enrique Padrós (2000, p. 59) denomina por "pedagogia do medo". Segundo Rouquié, ao longo do regime de Doutrina de Segurança Nacional no Uruguai foram feitos cerca de cinco mil prisioneiros políticos, quinze mil cidadãos perderam seus direitos, cerca de sessenta mil pessoas passaram pelas prisões. Desse total, apenas dois por cento não foi submetida à tortura. Com essa prática, procurou-se o envolvimento de toda a corporação militar com o rodízio de presos pelo maior número de dependências possíveis. Os militares lançaram-se no controle completo do poder após a destituição de Borbaderry em 1976, iniciando um processo de ato-institucionalização do regime. O conselho de ministros era civil, mas os militares passaram a ocupar todos os espaços, com a transformação dos “serviços públicos em casernas”(ROUQUIÉ, 1984, p. 302).

Já na Argentina, mais de duzentas mil pessoas exilaram-se fugindo do regime estabelecido após a ascensão ao poder do General Videla, que inaugurou o rodízio de juntas militares no poder em 1976. Os números oficiais, segundo informações da Comisión Nacional sobre Desaparición de Personas(CONADEP) ${ }^{3}$, apresentam a existência de cerca de nove mil mortos e desaparecidos, mas cogita-se, a partir de números apresentados pelas organizações dos direitos humanos, algo em torno de trinta mil pessoas (ROMERO, 2004, p. 210.). Cerca de trezentos e sessenta campos de tortura estiveram em funcionamento entre 1976 e 1983. O Regime de Segurança Nacional na Argentina apresentou um caso tragicamente inovador: o confisco de crianças, cujos pais "foram desaparecidos", ou presos. Também nesse país,os militares espalharam-se pelos principais órgãos da administração do Estado. O papel de destaque das Forças Armadas nessas ditaduras coloca em relevância a importância do conjunto de ideias que norteou o seu controle político: a Doutrina de Segurança Nacional.

\footnotetext{
${ }^{3}$ Responsável por uma intensa investigação sobre os “desaparecidos” pelos governos militares.
} 


\section{A origem da Doutrina de Segurança Nacional}

De maneira inicial, a Doutrina de Segurança Nacional apresentou-se como um corpo de princípios elaborados por civis norte-americanos do National Security People, nos Estados Unidos. Surgiu ao longo dos dez anos posteriores à Segunda Guerra Mundial e buscava responder tanto a uma demanda por um novo papel a ser desempenhado pelos EUA no cenário posterior a Segunda Guerra Mundial, quanto à perspectiva vigente dentre os policy makers norte-americanos de que a União Soviética, nesse novo contexto, apresentava-se tão expansionista quanto à Alemanha nazista havia sido às vésperas da II Guerra. Os motivos para essa suposição devem ser buscados na crença de que os movimentos comunistas grego e turco estavam sendo manipulados pelos soviéticos e de que a situação de destruição existente na Europa do pós-guerra viesse a possibilitar a disseminação do comunismo(LINK, 1965, p. 1165).

Nos Estados Unidos, sua formulação teve como um dos principais reflexos a hegemonia do executivo na elaboração da política externa norte-americana diante da necessidade de uma rápida resposta à ameaça nuclear, excluindo as prerrogativas dadas anteriormente ao Congresso americano. A DSN sustentou, ainda, uma política externa que se afastava do isolacionismo norte-americano característico dos períodos anteriores, na medida em que a disseminação de uma perspectiva de "real ameaça comunista" respaldava o novo papel que o governo buscava exercer no mundo: a consolidação de uma supremacia em boa parte obtida ao longo da II Guerra Mundial.

Outro desdobramento de destaque foi a montagem de todo um aparato burocrático-militar-industrial articulado a partir da sobrevalorização da segurança nacional. Por último, não se deve esquecer o clima de "caça às bruxas" sob a liderança do senador Joseph McCarthy, que se apresentou como símbolo da mais violenta onda anticomunista em larga escala, afetando a sociedade americana entre os anos 1948 e 1953. Perseguiu políticos, funcionários públicos e pessoas dos mais diversos extratos da sociedade americana. Segundo Arthur Link, em "graus diferentes, afetou a imprensa, as escolas, as igrejas, os tribunais e o Congresso", criando uma "atmosfera de medo" que 
College. Gradativamente uma política de contenção do comunismo estabelecida pelos EUA, ao longo das décadas de 1950 e 1960 propagou-se para a Europa, Ásia e para a América Latina. Nessa última região difundiu-se sob duas formas. A primeira, a partir das escolas militares que se destinavam a "melhor prepararem" os oficiais latino-americanos no combate ao comunismo. Através dos programas de assistência militar (MAP) o Southern Command coordenou e supervisionou uma influência crescente da assistência militar dos Estados Unidos, com a disseminação de uma série de "escolas" que visavam “colaborar" com a formação dos oficias das Forças Armadas dos mais diversos países da América Latina. Dentre estas escolas, citamos: a US Army Schooll of the Americas (em Fort Gullick), a Inter-American Geopolitic Survey Schooll (Fort Clayton), cursos de infantaria de Fort Benning ou os cursos de Estado-Maior de Fort Leavenworth, no Kansas. Observa-se ainda que, através de acordos militares multilaterais e bilaterais consolidados principalmente nas Conferências do México e do Rio de Janeiro, bem como de tratados como o Interamericano de Assistência Recíproca (TIAR) “além de armas e do treinamento vieram também as noções de segurança nacional e segurança coletivas" (ROUQUIÉ, 1984, p. 114).

Foi justamente no restante do continente que a Doutrina ganhou força e novos contornos. Apesar de sua propagação dar-se desde princípios de 1950, somente no fim do decênio ganhou ímpeto, graças ao papel francês na introdução de novos elementos e na sua disseminação. Coggliola (2001, p. 60) chega a assinalar que a doutrinação militar francesa se desenvolvia na Argentina desde 1957. A DSN esteve presente numa vertente do pensamento militar francês envolvida diretamente nos conflitos coloniais na Indochina e no Magreb. Para os franceses, o questionamento das populações coloniais seria um desdobramento da influência soviética, que se realizava sob uma nova forma.

Segundo esses militares, a estratégia soviética de propagação do comunismo aproveitava-se dos conflitos coloniais e dos problemas do Terceiro Mundo para estimular a subversão e o aparecimento de conflitos internos com objetivo de conquista do poder, 
por parte dos movimentos comunistas locais. Os franceses, como resultado dessa forma de entender as lutas coloniais, realizaram a inserção de um novo conceito ao corpo da Doutrina: a ideia de Guerra Revolucionária e de Guerra Insurrecional. Segundo essa perspectiva, o papel soviético seria o de infiltrar agentes junto a essas populações, assim como fornecer o instrumental teórico para a análise das realidades regionais.

Deve ser lembrado, ainda, que a Doutrina de Segurança Nacional apropriou-se e reformulou ideias e conceitos pré-existentes, tais como o anticomunismo latente das elites latino-americanas, assim como a concepção de geopolítica. Na América Latina, essa Doutrina encontrou sua potencialização máxima. Diferentes perspectivas sobre a mesma podem ser observadas em quatro obras que, no meu entendimento, são fundamentais para a compreensão do seu papel nas ditaduras estabelecidas ao longo dos anos 1960 e 1970. São elas, na ordem de publicação: Ideologia de Segurança Nacional, elaborada por Joseph Combin em 1979; El terrorismo de Estado - La Doctrina de la Seguridad Nacional em el Cono Sur, publicado em 1980 por Jorge Tapia Valdés; El Pensamiento Político de los Militares, de Genaro Arriagada Herrera ${ }^{4}$ e desenvolvida no ano de 1981; e, por último, 0 Estado Militar na América Latina, elaborada em $1982^{5}$ por Alain Rouquié. ${ }^{6}$

\section{Combline a primeira sistematização da Doutrina de Segurança Nacional}

Uma das primeiras obras sobre o tema foi o trabalho desenvolvido pelo Padre Joseph Comblin, intitulada Ideologia de Segurança Nacional (1979). Um dos criadores da “Teologia da Libertação”, o padre belga trabalhou na América Latina desde 1948. Militante da esquerda católica foi expulso do Brasil em 1971, exilando-se no Chile de onde também foi expulso por Pinochet em 1980.

\footnotetext{
${ }^{4}$ A primeira edição da obra é de 1981. Utilizo aqui a segunda edição, de 1986.

${ }^{5}$ O livro foi lançado em 1982 pels Editions Du Seiuil. Utilizo aqui a primeira edição brasileira, da Editora AlfaOmega,

${ }^{6}$ Não inclui aqui obras que, apesar de fazerem referência à Doutrina de Segurança Nacional, não canalizaram sua atenção na direção de um esforço descritivo desse conjunto de ideias. Esse seria o caso da obra de Oliveira (1976).
} 
Segundo Comblin, a Ideologia de Segurança Nacional resultou basicamente de um processo de desnacionalização da vida política e econômica dos países latino-americanos. Foi o elemento central para a configuração de um Estado forte, centralizado e com uma imensa capacidade de impor a ordem social. Apresentava-se como um conjunto de referências coerente e articulado, que se apresentou como central para a compreensão do mundo no extremo ocidente por parte das direitas. Por esse motivo, Comblin concebe esse corpo de ideias como uma ideologia.

O autor aponta o que considero como os dois princípios fundamentais, a partir dos quais a DSN estabeleceu um mapeamento do mundo: as noções de geopolítica e de guerra total. A geopolítica seria a ciência que teria por função o estudo da relação entre geografia e os Estados. Se antes era utilizada como um instrumento auxiliar para o estabelecimento das estratégias a serem adotadas por um Estado - tanto no plano interno da mobilização de recursos, quanto no plano externo das relações internacionais , com a DSN a geopolítica ganhou novos contornos, apresentando-se com uma função definidora da vocação de uma nação. Nela os Estados deveriam procurar "os sinais de seu destino".

Segundo Comblin, no plano externo, a grande "tese geopolítica é a divisão do mundo em dois poderes antagônicos e a inevitável integração da América Latina em um desses blocos, por motivos geopolíticos” (COMBLIN, 1979, p. 28). Associava automaticamente o "mundo ocidental" a um conjunto de características que seriam a propriedade privada, a cultura greco-romana, o cristianismo e o liberalismo. A geopolítica apropriada pela DSN assinalava que, uma vez situados no ocidente, esses traços seriam os elementos inerentes à cultura de uma nação.

Já no plano interno, a geopolítica estabelecia uma identificação absoluta entre Estado e Nação. A nação passava a ser concebida dentro de uma perspectiva organicista, como ente vivo dotado de vontade única onde os conflitos sociais desaparecem. Segundo a Doutrina, o Estado seria o único a possuir uma capacidade efetiva de interpretação dessa vontade. 
Outro princípio central dentro da DSN seria a noção de Guerra Total. As guerras modernas seriam marcadas pela utilização de recursos ilimitados, tanto humanos quanto materiais, para a consecução de seus objetivos de vitória. Tratava-se mesmo de uma luta pela própria sobrevivência em um cenário caracterizado pela existência de armas nucleares e de exércitos convencionais compostos por milhares de homens. O confronto entre capitalismo e comunismo seria o exemplo concreto desse novo contexto. Afinal, a bipolaridade levaria à guerra total, já que ela seria generalizada e absoluta para enfrentar o adversário. Segundo Comblin, os “doutrinários da Segurança Nacional afirmam que toda a guerra contra o comunismo é, necessariamente, uma guerra pela sobrevivência" (COMBLIN, 1979, p. 38).

Além disso, os soviéticos estariam a desenvolver novas técnicas de expansão que visavam minar internamente os Estados adversários. Denominada genericamente de “Guerra Revolucionária ou Insurrecional”, a técnica consistiria em propagar o caos e a desordem através de uma ação indireta que objetivava diminuir, ou mesmo eliminar a capacidade de sobrevivência das nações capitalistas. Sob o prisma da "Guerra Revolucionária" Comblin aponta que ocorreria o desaparecimento completo das diferenças entre subversão, crítica, oposição política, guerrilha e terrorismo, tendo em vista que tudo isso seria manifestação de um único fenômeno.

Nova técnica de guerra que amplificava a perspectiva de "Guerra Total" porque levava o confronto para todos os âmbitos da vida social, a "Guerra Revolucionária" “disseminada” pela União Soviética intentaria obter o controle da população pelo terror. Nesse sentido, o contra-terrorismo, defendia a Doutrina, deveria empreender o mesmo caminho para neutralizar a ação dos comunistas. Simultaneamente, exerceria o controle necessário para atingir o que na DSN denominava-se por "Objetivos Nacionais". Como etapas desse processo contrarrevolucionário colocavam-se, de forma sequencial, a identificação e eliminação dos simpatizantes do comunismo, a detecção dos membros da subversão e, por último, o extermínio desse núcleo central da oposição subversiva. Tudo isso acompanhado pelo desenvolvimento de ações cívicas que buscariam retirar a população da órbita de influência comunista. Para todas essas etapas era de extrema 
importância o trabalho de inteligência e informação, ainda que com a utilização da tortura.

Essa ação possibilitaria que os recursos da nação - os "Poderes Nacionais" fossem eficazmente mobilizados para alcançar os "seus objetivos", relacionados diretamente à vocação que uma nação situada no ocidente possuiria: cristianismo, liberalismo, propriedade privada e cultura greco-romana. Divididos em quatro modalidades - poder econômico, poder militar, poder político e poder psicossocial -, deveriam ser controlados e empregados para atingir suas metas, através de uma estratégia a ser definida pelos intérpretes da vontade da nação. Por sua vez, a garantia proporcionada para que os objetivos fossem atingidos era denominada por "Segurança Nacional". Para que as forças do "Poder Nacional" fossem mais bem mobilizadas não caberia a possibilidade de divergências, ou oposições uma vez que isso dizia respeito a interesses particulares, e viabilizaria a emergência do comunismo. Nesse sentido, todo questionamento é concebido como ato de subversão que afeta diretamente na capacidade do Estado em atingir seus objetivos fundamentais.

Como a situação é caracterizada por um contexto de guerra, mesmo a política passou a ser vista a partir desse prisma, invertendo a máxima de Clausewitz, passando ser a política a continuação da guerra por outros meios. Porém, nesse confronto generalizado e total que caracterizaria a guerra fria, aos exércitos latinoamericanos não caberia a responsabilidade pelo confronto nuclear. Assevera Comblin que:

Os Estados Unidos iam ensinar a todos os seus satélites que a segurança coletiva do mundo livre repousa sobre uma certa divisão do trabalho: os EUA assumem sozinhos a responsabilidade da dissuasão nuclear; porém os satélites devem se encarregar - com a ajuda americana - de lutar contra a guerra revolucionária dentro de suas fronteiras(COMBLIN, 1979, p. 114).

A perspectiva de Comblin sobre a Doutrina de Segurança Nacional está associada diretamente à caracterização de que ela se apresenta como um instrumento da dominação norte-americana pelo mundo. Por esse motivo, o elemento central da análise está no papel de sua propagação na América Latina, principalmente após a ocorrência da Revolução Cubana. 
Comblin chega a identificar a presença de escritos franceses e sua influência na disseminação da DSN. No entanto, ao final, conclui ser incontestável que essa doutrina vem diretamente dos Estados Unidos. Mesmo o conceito de Guerra Revolucionária resultaria das "meditações" de homens do National Secutiry People acerca dos escritos de Mao, Ho Chi-minh, Giap e Guevara?

Já a função das elites militares latino-americanas, teria sido a de meras implantadoras das técnicas que, sob a tutela norte-americana, desencadeariam a contrarrevolução. Exportada pelos Estados Unidos,

nem Pinochet nem Banzer optaram por aplicar em seus países a Doutrina de Segurança Nacional. Fizeram-no, entretanto, como se obedecessem a uma necessidade lógica de seu sistema estatal. Podemos afirmar, portanto, que a Doutrina da Segurança Nacional, vinda do exterior, em vez de passar por um processo de rejeição devido às particularidades dos países envolvidos, resulta, na realidade, em uma desnacionalização da vida social e política de cada um deles, ao ponto de dar a impressão de que, nesses regimes, a sociedade escapa ao controle do homem(COMBLIN, 1979, p. 16).

Assim, a difusão da DSN é considerada como o meio através do qual os Estados Unidos insuflaram, nos anos 1960 e 1970, a afirmação de ditaduras militares objetivando a subordinação dos diferentes interesses nacionais aos seus interesses de nação imperial. A análise potencializa, dessa forma, a capacidade do trabalho de inculcação ideológica norte-americana desempenhado pelas suas escolas militares na consolidação de uma perspectiva de mundo profundamente anticomunista e caracterizado pela desmobilização social. Uma política calcada no sacrifício dos trabalhadores em nome de uma minoria.

Por sua vez, concebia que os grandes beneficiários do Estado de Segurança seriam as empresas multinacionais junto com a burguesia vinculada as empresas estatais, pólos dominantes da sociedade fundada na DSN. Ainda que se afirme que o liberalismo dos Estados, os quais adotaram a DSN seja de fachada, reforça por diversos momentos que o papel protagônico no plano econômico foi o do capital internacional. Seus interesses

\footnotetext{
7 São lideranças políticas respectivamente da Revolução Chinesa (Mao), da guerra de descolonização da Indochina (Ho Chi-minh e Giap) e da Revolução Cubana (Guevara)
} 

Comblin. O papel desempenhado pelos militares foi tão somente instrumental para o atendimento do interesse do capital internacional norte-americano. A função das escolas militares seria a de difundir uma perspectiva sobre o mundo político, na qual caberia às Forças Armadas uma função de proeminência no mundo político, dada a sua subordinação instrumental aos interesses da burguesia.

\section{A DSN como fascismo dependente}

Outro caminho de análise é percorrido por Jorge Tapia Valdés. Ministro da Educação do governo Allende nos anos de 1972 e 1973 foi professor de Direito Constitucional e Doutrina Política na Universidade do Chile. No momento em que escreveu a obra que analisarei aqui - El terrorismo de Estado - La Doctrina de la Seguridad Nacional en el ConoSur-, ministrava aulas no curso de pós-graduação em direito na Universidad Zulia, na Venezuela.

Tal como Comblin, o autor assinala que a Doutrina originou-se nos Estados Unidos como parte de um projeto internacional de afirmação da hegemonia norte-americana no “mundo ocidental”. A opção por encaminhar a propagação da DSN teria sido resultado da percepção das elites norte-americanas de que não seriam capazes de motivar e mobilizar outras sociedades em torno de seu modelo, em uma situação na qual a “consciência sociopolítica”e as "expectativas maduraban aceleradamente" (VALDÉS, 1980, P. 45). Através de uma mensagem subliminar, os Estados Unidos teriam realizado um trabalho de doutrinamento ideológico que visava eliminar as contradições entre os interesses dos EUA e os das diversas nações do "extremo ocidente".Como Comblin, considera que sua difusão desenvolveu-se a partir das escolas militares norte-americanas dentre a oficialidade dos países situados ao sul do Rio Grande. No entanto, enfatiza mais o papel desempenhado pelas elites civis de direita com conotações fascistas nessa ação de propagação. 
Valdés, considera a Doutrina de Segurança Nacional como um corpo de ideias articuladas em torno de um sistema coerente que difundia uma dada forma de se pensar a política, a economia e a sociedade. O ponto de partida da DSN seria a geopolítica, apresentada como ciência que instrumentalizou a geografia para fins políticos. Serviu para "fusionar y estandarizar a la población en torno a un proyecto monista" na medida em que estabelecia que o destino de uma nação encontrava-se de certa forma predeterminado(VALDÉS, 1980, p. 26).

No plano político, a Doutrina defendia a inexistência de outra forma de política senão a guerra, o que favorecia o controle pretendido e efetivado pelos militares na vida política. Isso era complementado pela desvalorização da competência das elites civis para o exercício do poder. Além disso, assinalava a incapacidade da democracia em defenderse da grande ofensiva que estaria sendo engendrada pelo movimento comunista internacional, capitaneada pela União Soviética, numa situação em que toda oposição passou a ser vinculada a esse verniz ideológico. A Doutrina Nixon, proferida em 1957 acompanhava essa avaliação, na medida em que afirmava que a instabilidade resultava de problemas oriundos do universo das instituições políticas existentes na América Latina e que contribuíam para a subversão. A proposta de participação de militares na vida política apresentava-se como parte mesmo da uma doutrina oficial nos EUA.

Para a Doutrina era necessário conter aqueles que se opunham a internalizar o que consideravam uma "conduta aceitável”. Os fatores adversos que impediram a nação de alcançar seus objetivos são enquadrados em três modalidades: impedimentos, antagonismos e pressões. O primeiro teria caráter involuntário, o segundo seria marcado pela intencionalidade e, o terceiro quando, além da intencionalidade em resistir à “conduta aceitável” dispunha de meios, quaisquer que fossem, para se opor (VALDÉS, 1980, p. 120).Independentemente do tipo de fator, todos os que colaboravam para o seu desenvolvimento eram considerados como inimigos internos. A legitimidade do regime seria baseada no objetivo que se almejava alcançar e nos elementos que garantiriam o sucesso dessa trajetória: a autoridade obtida através da política, da censura e da violência. 
As expectativas da aliança militar-tecnocrática criada em torno desse conjunto de ideias era a obtenção da estabilidade com a criação de um regime não democrático, autoritário e repressivo. No plano econômico, a aplicação do liberalismo com a defesa da propriedade privada e da livre empresa. Já no que se refere à dimensão social, objetivavase a ordem e disciplina.

A pretensão norte-americana com a difusão da doutrina não estaria somente na contenção do comunismo, mas também na defesa dos interesses vinculados ao capital das multinacionais norte-americanas em associação com uma burguesia vinculada a esses setores. Outro segmento a se beneficiar era uma elite técnico-empresarial que participava dos processos decisórios e servia de nexo com os setores civis e nacionais. É certo que a defesa da propriedade privada e do sistema capitalista atendia também aos reclames do restante da burguesia nacional, mas essa é considerada pelo autor mais como objeto do que sujeito do processo. A meta seria, em última instância, a defesa da livre empresa.

Os militares se apresentam, dessa forma, como instrumento de classe da grande burguesia. Uma das estratégias da DSN (a primeira seria a repressão e a segunda a doutrinária), visava beneficiar o capital nacional e internacional através de uma "drástica redistribución del ingresso realizada a expensas de los trabajadores"(VALDÉS, 1980, p. 234). Demonstrava-se assim, afirma o autor, o fundamento do modo de inserção "del capitalismo dependiente em la actual etapa de desarrollo del capitalismo transnacional" (VALDÉS, 1980, p. 249).

Um elemento central dentro da perspectiva de Valdés que o distancia da análise de Comblin é a sua concepção de que a Doutrina de Segurança Nacional seria resultante da existência de um fascismo dependente nos países da América Latina. Tal como em sua matriz europeia, para Valdés seria uma doutrina política que "se funda en una serie de principios y propone un conjunto de medios dirigidos al gobierno total de la sociedad"(VALDÉS, 1980, p. 165). Tratava-se de uma síntese e integração que abarcava todos os assuntos nacionais. Marcava-se pela separação entre política e direito, em que a elite desfrutava de uma esfera de liberdade e de um poder sem limites nem responsabilidades. Afirma existir uma semelhança, senão uma identidade entre os 
uma ditadura de minorias para defesa dos interesses de uma minoria, definição central do fascismo para o autor. A justificativa

filosófica y ética estará siempre asentada en la primacía de la voluntad y la acción, sobre la razón y la norma; en la desigualdad humana y la concepción elitista; en el pragmatismo y antidoctrinarismo; en el antipluraismo y en la fe en la unidad política nacional; en la desconfianza en el principio democrático y el principio mayoritario, y en la primacía del espíritu bélico sobre el pacifismo(VALDÉS, 1980, p. 281).

De caráter totalitário, seria uma "respuesta irracional al miedo de las derechas, frente al ascenso de la anti hegemonia"(VALDÉS, 1980, p. 17). O aparato criado pela Doutrina avisava a subjugação completa da população, em todos os níveis, "de cada aspecto de la vida de todos los hombres y de todo el hombre" (VALDÉS, 1980, p. 27) através de um "cuerpo sistemático de principios y creencias, una metodologia para determinarlos y una estratégia para ponerlos en práctica y asegurar su cumplimiento"(VALDÉS, 1980, p. 102).

Para Tapia, o conhecimento da relação, nos regimes fascistas, entre estado e direito possibilita a compreensão da própria DSN. No nazi-fascismo, a política funciona a partir do binômio amigo-inimigo,em que o outro é concebido como um estrangeiro que deve ser combatido. A função do Estado seria identificá-lo e eliminá-lo. O mesmo se desenvolveria dentro do regime implementado pela DSN, em que o estado de emergência passa a ser uma normalidade que viabilizaria a "extirpação do mal”. Dessa forma, desarticula-se o sistema jurídico e a hierarquização de normas e valores, também jurídicos.

O direito é estabelecido pelo líder, permanecendo o funcionamento do sistema jurídico somente no plano "interindividual” e, no plano econômico, principalmente no que se refere a propriedade privada. A única liberdade vigente é a econômica e o único direito é o do empresariado, sendo ilhas de legalidade. A opinião dos tribunais só será 
O fascismo latino-americano seria semelhante ao balcânico da década de 1930, estabelecido não de baixo para cima, com participação das “massas”, mas sim de cima para baixo, por meio do aparato do Estado e apoiado pela força militar da burguesia bem como submetido aos seus interesses. A crise hegemônica da burguesia e a falta de controle do aparato estatal pela fração dominante, "caldo de cultura" para o seu aparecimento,seriam características básicas que estariam a se desenvolver na América Latina nos anos de 1960 e 1970.

O terror tornava-se o principal instrumento de obtenção dos objetivos políticos, ferramenta básica para a subordinação da sociedade adotando a detenção arbitrária, o desaparecimento, o assassinato e os campos de concentração. O controle de todo homem e de todo o homem é almejado também através da internalização dos princípios por eles defendidos, possibilitado pelos meios de comunicação massiva e pelo sistema educacional colocado em maior, ou menor grau sob o controle do Estado, e sob intensa infiltração.

No entanto, esse fascismo apresentaria características particulares, uma vez que resultante não das demandas da burguesia nacional, mas antes das necessidades da potência hegemônica da região. Nesse sentido, a DSN se caracterizaria como um fenômeno atípico, porque além de efetivar-se de cima para baixo, seria fruto de pressões externas. Outro aspecto que colabora para que, em alguns momentos, Valdés desenvolva um caminho que o distancia um pouco de Comblin, refere-se ao papel desempenhado pelas elites nacionais. O Autor reitera, por algumas vezes, que não intenciona apontar a DSN como influência “directa, rectilinea y exclusiva” dos EUA (VALDÉS, 1980, p. 98). A configuração da DSN se daria também em função da ação das elites nacionais e não teria sido fruto tão somente da política externa norte-americana. As elites nacionais possuíam um grau de autonomia significativa, já que são "ellos los que en definitiva escogen y desarrollanla DSN como "imprescindible fundamento teórico de suplan de restauración social”(VALDÉS, 1980, p. 280). Afirma em dado momento que, apesar de a aliança militar- 
tecnocrática perceber que o interesse dos norte-americanos era eminentemente, 0 estabelecimento de regimes estáveis capazes de impor ordem e paz social, ainda assim isso estaria dentro do quadro de interesses desses setores sociais, na medida em que possibilitaria a sua recuperação da hegemonia política. E afirma:

\begin{abstract}
Hechas estas precisiones, podemos comprender que el fascismo dependiente se configura tanto a partir de las políticas y doctrinas concretas e expresas puestas en práctica por el Pentágono y el complejo militar-industrial - una forma de dependencia manifiesta -, cuanto en función de las percepciones, actitudes y prácticas de las élites nacionales que se esfuerzan por crear o restaurar las condiciones de su propia subsistencia como tales y como partes del sistema imperialista globalmente considerado. (...). En este sentido, es forzoso reconocer un grado importante de autonomía a los centros formales y reales de poder del país dependiente. (VALDÉS, 1980, p. 280).
\end{abstract}

No entanto, acaba por predominar, no meu entendimento, a ideia de que a DSN busca atender as necessidades de enquadramento buscadas pela potência hegemônica. Diversos são os momentos que apontam nessa direção. Embora afirme que as causas da intervenção militar no Chile tenham sido internas, considera que a forma pela qual a mesma se desenvolveu teve raízes externas que, inclusive, levaram a superação da doutrina militar chilena, o que comprovaria sua “naturaleza foránea”.Valdés afirma ainda que a Doutrina, exportada pelos Estados Unidos, teve importância fundamental na definição do comunismo como inimigo das Forças Armadas, aspecto central para o estabelecimento de ditaduras na região.

\title{
As elites nacionais entram definitivamente em cena
}

Genaro Arriagada Herrera elabora outra obra na sequência da publicação do trabalho de Valdés, intitulada El pensamiento político de los militares, sua primeira edição data de 1981. Advogado e cientista político foi ministro do governo de Eduardo Frei. Entre os anos de 1978 e 1979 esteve vinculado, como pesquisador, ao Wilson International Center for Scholars, em Washington. Seu trabalho foi financiado pelos institutos Woodrow Wilson, Fundação Adenauer (Alemanha) e pelo Centro de Investigações socioeconômicas da Cia de Jesus. 
A análise percorre o caminho das características institucionais - tais como profissão, organização e estilo de vida -, que estariam presentes nas Forças Armadas latino-americanas, mais especificamente nos exércitos. Avalia a perspectiva dos militares frente à sociedade civil e ao poder político. Sua abordagem tem como recorte um período anterior e mais amplo para entender as ditaduras civil-militares dos anos 1960 e 1970, uma vez que avalia que parte expressiva das características institucionais presentes nas Forças Armadas desse período, originaram-se com a efetivação das missões militares germânica e francesa na América Latina.

Afirma o autor que as Forças Armadas seriam instituições marcadas por um enquadramento de alto grau de seus membros, sendo uma profissão a apresentar um corpo de conhecimento específico e um sistema educacional e de treinamento particulares. Esses aspectos colaborariam para a constituição de uma identidade que os afastaria do conjunto da sociedade, estabelecendo como limite um antagonismo com o mundo civil. Por conta de sua estrutura altamente hierarquizada, possuiria um significativo desprezo pela democracia. Essas seriam, portanto, características presentes na instituição antes mesmo de sua disseminação por parte da Doutrina de Segurança Nacional na região. Isolamento, culto à virilidade e rudeza teriam estimulado ainda um sentimento de superioridade.

Assim, esses traços teriam sido resultantes das missões militares estrangeiras iniciadas em fins do século XIX e princípios do século $X X^{8}$. A contratação da missão germânica pelo Chile desencadeou uma prática reativa seguida por outras nações da região.Nesse momento, disseminou-se entre os militares de boa parte dos países latinoamericanos tanto uma valorativa identidade institucional quanto uma visão depreciativa do mundo civil. Com essas missões militares vieram não apenas novas formas de

\footnotetext{
${ }^{8} \mathrm{~A}$ primeira missão militar estrangeira foi contratada pelos chilenos, temerosos do revanchismo peruano e boliviano após sua vitória militar sobre esses países na Guerra do Pacífico. Visava a modernização das forças armadas em um mundo marcado pelo desenvolvimento das práticas imperialistas europeias de fins do século XIX. No Chile, a modernização se inicia no ano de 1894 com uma missão germânica. De forma reativa, temendo que o Chile alcançasse uma superioridade militar que colocasse em risco a segurança do país, os argentinos contrataram também uma missão germânica. Brasil, Uruguai e Bolívia contrataram missões militares francesas. Já Equador, El Salvador e Colômbia adotaram um processo de "terceirização" para efetuarem seus processos de modernização, utilizando-se do conhecimento chileno adquirido nesse momento.
} 

parlamento, com o movimento operário e o socialismo, tidos como anti-patriotas e inimigos do exército. Isso os associava com uma ameaça contra a ordem. Existia na Alemanha daquele momento um intenso debate relativo ao pacifismo e à convocação obrigatória, aspectos que eram colocados em pauta e que situavam em lados distintos o movimento socialista de fins do XIX, princípios do XX e as Forças Armadas do país.

A propagação dessa cultura na região, não teria se efetivado no vazio, por simples reprodução, uma vez que no Chile também se observava uma grande influência socialista e anarquista, bem como a presença das mesmas questões colocadas na Europa acerca da conscrição e do pacifismo. Nesse sentido, a influência das ideias presentes no exercito alemão - de que o socialismo, bem como o anarquismo, eram ameaçadores a sua existência dado seus discursos -, adicionada ao contexto político chileno ainda que com proporções diferenciadas, teriam colaborado para o desenvolvimento do anticomunismo no meio militar nesse país.

A origem da influência da geopolítica com sua disseminação pelos exércitos latinoamericanos teria ocorrido também nesse momento. Segundo Arriagada, a Geopolítica encontrou na Alemanha um campo fértil de formulação. Profundamente marcada por uma concepção organicista em sua origem ${ }^{9}$, defendia a necessidade do estabelecimento de um espaço vital, mas também de coesão interna para que a sobrevivência da nação fosse viabilizada. O Estado era encarado como um ser dotado de objetivos próprios, diante dos quais a vontade e intenção humanas teriam que se submeter. Modificava, inclusive, o próprio papel da geografia "que, bajo su impulso, dejaba de ser una mera ciência descritiva para converterse en un instrumento de acción” (HERRERA, 1986, p.112).A ideia de um Estado,enquanto ente biológico, apresentava como desdobramento

\footnotetext{
${ }^{9}$ Nessa concepção o Estado é entendido como um ente vivo, que nasce, cresce, "morre" e é dotada de vontade própria. O darwinismo social colaborou para o estabelecimento de uma associação entre as leis que regem a biologia e aquelas que regem as Nações. Ambos estariam diretamente envolvidos na luta pela sobrevivência(HERRERA, 1986, p 112).
} 
que, na sua luta pela sobrevivência, teria que potencializar o controle e a organização dos seus recursos visando ampliar o poder necessário para crescer. De outro lado, a geopolítica também se difundiu naquelas nações que tiveram esse processo de modernização pela via francesa. No exército francês, em finais do XIX e princípios do XX, a geopolítica aparecia como uma ciência política que defendia a expansão física mas também a segurança e desenvolvimento.

Nos países latino-americanos, a ênfase na necessidade de espaço vital foi deslocada pela valorização da unidade interna. Tratou-se de uma readaptação decorrente do contexto diferenciado entre a Europa e a região, segundo Herrera. Nessa concepção, já se manifestava a identificação de alguns elementos que poderiam contribuir para a obstrução do caminho do Estado na direção de seu fortalecimento e crescimento. $O$ principal deles seriam as lutas intestinas. Comunismo, e mesmo a democracia, apareciam como elementos que levavam ao enfraquecimento já que estimulavam o confronto político que debilitava as instituições nacionais.

Apesar de a primeira difusão da geopolítica na América Latina datar da fase de modernização do Exército, foi nos anos 30 e 40 que sua influência se manifestou de forma mais intensa, assumindo ares de ciência. Nessa perspectiva, a população seria “mero instrumiento o recurso al servicio de la política de poder del Estado"(HERRERA, 1986, p. 137).O objetivo da geopolítica seria viabilizar a obtenção da segurança integral, ou seja, "del conjunto de circunstancias que configura la salud del Estado, los procedimientos para vigilarla y detectar oportuniamente las 'enfermidades' y las medidas de tratamiento que deben aplicarse para assegurarle una evolución larga, segura y normal"(HERRERA, 1986, p. 139).

A partir dos anos 1950 o autor afirma ter se desenvolvido um processo de recuperação desses princípios após o desprestígio momentâneo, que se processou no pós-II Guerra Mundial em função da associação feita com o nazi-fascismo. Essa retomada se articulou a partir de uma fonte diferenciada: a Doutrina de Segurança Nacional. A ideia da ameaça de uma agressão comunista começou a tomar corpo aceleradamente. Esta perspectiva seria fruto da influência que o pensamento estratégico de nações como os EUA e a França passaram a exercer sobre a cultura política militar nos países da América 
Latina ao longo desse período. O conflito leste-oeste se desenvolvia, agora, nessa perspectiva, no espaço do terceiro mundo. A conquista desses países pelo comunismo era apresentada como iminente,ameaçando a segurança e a integridade dos Estados da região.

Propagava-se uma percepção de que a subversão seria um ato de pura maldade que, contraposto ao messianismo militar, inseria o problema dentro de um quadro de luta entre o bem e o mal. A situação agravava-se em função da caracterização que era feita sobre o povo, visto como facilmente controlável diante da hábil manipulação por parte do movimento comunista internacional e seus instrumentos de propaganda extremamente eficazes. Além disso, para além dos comunistas, existiriam os “criptocomunistas”, os "procomunistas”, e os “"compañeros de ruta' y de los'idiotas utilizables"” associados a grupos estimulados por diferentes motivos: “ambición, pusilanimidad, snobismo, fidelidad, interesesprofesionales o econômicos, etc" (HERRERA, 1986 p. 177).

O confronto, assinalava o ideário francês, atingiria a todos e se realizaria em todos os ambientes: social, econômico, político e cultural. Nesse sentido, era apresentado como uma guerra total. O anticomunismo de princípios do século e a geopolítica teriam se rearticulado então em um conjunto mais estruturado "na forma de uma teoria militar consistente", que seria a Doutrina de Segurança Nacional. Para Herrera, isso se efetuou não por ação dos Estados Unidos, como apontam Comblin e Valdés, mas com base na “doctrina contrasubversiva francesa”, por oficiais desse país envolvidos diretamente tanto na guerra da Indochina quanto na da Argélia.

Para uma defesa eficaz diante desta nova tática comunista, o ocidente deveria se utilizar das técnicas dos inimigos, principalmente no que se referia à propaganda, doutrinação e organização. Os EUA aparecem, na avaliação de Herrera, como difusores da DSN e não como seus formuladores. A disseminação se dava sob variadas formas: decisão institucional (caso da Argentina e do Brasil), divulgação por editoras privadas ${ }^{10}$ dessas nações e através do treinamento militar estadunidense.

\footnotetext{
${ }^{10}$ Segundo Herrera, o exemplo dessa divulgação se observa na proliferação das obras literárias do novelista
} 
Os norte-americanos teriam elaborado uma doutrina contra-subversivatão somente nos idos da década de 1960. Apresentavam em comum com os franceses a ideia de um "contexto estratégico general en que se ubicavan las guerras subversivas" (HERRERA, 1986, p. 189).Existiria um novo cenário, propagava essas perspectiva, "una amenaza comunista global y ella revistiría la forma de pequenas guerras irregulares, no convencionales, centradas en técnicas de guerrilla, que se librarían em los paises de la periferia" e se que fundamentava numa visão conspirativa da história(HERRERA, 1986, p. 189).A legitimação da violência advinha da ideia de que, em uma guerra total, todos os recursos deveriam ser utilizados contra a subversão, o que era explicado pela ação comunista que inviabilizaria as regras oficiais de guerra.

Ao término de seu trabalho Herrera apresentara ser um equívoco considerar que a ideologia seja o aspecto definidor da política. Considera que os fatores históricos, políticos, culturais, econômicos e sociais contribuem para explicar a realidade e, acrescento eu, a entender a forma pela qual essas perspectivas de mundo tornam-se "reais". A ideologia, afirma o autor, se apresenta como uma das variáveis a explicar a conduta política de qualquer ator social. Nesse sentido, não "sería exagerado negar la enorme importancia de las ideologías sobre la acción”(HERRERA, 1986, p. 211).

\section{A relativização da importância da DSN}

A obra de Alain Rouquié - O Estado Militar na América Latina -, datada de 1982 em sua primeira edição, busca explicar os regimes civil-militares através de uma abordagem institucional das Forças Armadas que identifica a efetivação de um processo de militarização da política. Na sua análise, o autor apresenta uma genealogia das instituições militares e da estruturação do próprio Estado, processo que se desenvolve em três grandes fases. A primeira seria demarcada pela existência de um militarismo sem militares, a segunda caracterizada pela presença de militares sem militarismo, e a terceira,

Jean Larteguy: Los Centuriones e Los Petrorianos, que eram impressos no Brasil, na Argentina, Chile e Uruguai. (IDEM, p. 186-188). 
que o autor aponta como sendo de militarismo com militares ${ }^{11}$. Passada a fase da independência e seu prolongamento pelo século XIX, dois objetivos são observados no final desse século: a profissionalização dos militares e a modernização das Forças Armadas com a contratação das missões militares estrangeiras.

Segundo Rouquié esse processo ocasionou uma progressiva diminuição dos vínculos entre o universo militar com o restante da sociedade e o aparecimento de uma lógica organizacional própria, a qual contribuiu para um novo interesse pela política. Aponta que ela se fundamentou no fornecimento de armas, treinamento militar, organização da defesa nacional e elaboração deuma doutrina de guerra. Junto com isso, vieram as perspectivas de mundo que marcavam os oficiais franceses e germânicos das missões estrangeiras. Essa influência, no plano da cultura política, dar-se-ia pela sedimentação de uma tradição aristocrática e do desprezo pelos sistemas representativos. Portanto, Rouquié retoma a importância dessa modernização apresentada por Herrera.

No entanto, o autor adiciona novos ingredientes a essa análise. Ao longo deste processo iniciado com a independência, as Forças Armadas adquiriram responsabilidades cívicas e nacionais baseadas em três objetivos: centralizar o poder para acabar com a dispersão geográfica e sua impotência diante das rebeliões indígenas; controlar o conjunto do território nacional, como representante legítimo do Estado; e, por último, buscar a integração étnica e social para criar a noção de comunidade. Esses objetivos, aliados a inexistência de conflitos externos colaboraram, segundo o autor, para uma politização do ambiente militar e para uma preocupação, acima de tudo, com a existência de um inimigo interno. Não o comunismo, mas o "povo". Isso, antes mesmo da influência da DSN.

\footnotetext{
${ }^{11}$ Para o autor depois da independência observa-se uma fase onde existia um vazio institucionalque colaborou para uma vida política militarizada e violenta (fase do militarismo sem militares). A segunda fase desenvolveu-se quando o Estado se cristalizou, mas antes de se estabilizar criou um exército nacional, cujos quadros são saídos da classe dirigente (militares sem militarismo). A terceira fase iniciouse no século XX, quando os militares são militarizados "para se estabilizar melhor as Forças armadas" e com isso, obter recursos para interferir na vida política. (ROUQUIÉ, 1984., p. 60 e 61).
} 
Avançando para a segunda metade do século XX, Rouquié opta por fazer uma discussão que se centraliza no papel que a Doutrina de Segurança Nacional teria apresentado na região. Indica o seu caráter instrumental para o mundo militar, na medida em que ratificava seu papel de assegurar a ordem e contribuía para a otimização da exploração econômica por parte da Europa, mas principalmente pelos Estados Unidos. Considera que a relação da potência hegemônica com a América Latina afirmou-se, enquanto interesse, apenas a partir de fins do século XIX, quando Destino Manifesto norte-americano dentro do continente já havia se completado.

A política de Boa Vizinhança favoreceu o aparecimento do apoio aos EUA na II Grande Guerra, período em que o país consolidou sua influência econômica, militar e política que vinha se desenvolvendo desde a década de 1920. Com o término do conflito, essa estrutura afirmou-se através de uma série de tratados bilaterais e multilaterais de segurança. O entendimento norte-americano de que a Revolução Cubana desencadeava a presença do perigo comunista no extremo ocidente modificou os seus interesses estratégicos, redirecionando-os mais intensamente para a região. As relações entre as Forças Armadas latino-americanas e o país aprofundaram-se por sua iniciativa, com a intensificação dos programas de apoio militar e o aumento do número de oficiais latinoamericanos que eram convidados a realizar estágios em escolas ou centros de treinamento dos EUA.

Os cursos reforçavam o alarmismo insurrecional, a ameaça comunista e o espírito de cruzada. Através de uma mensagem subliminar, que por vezes tornava-se explícita, visavam ainda "reforçar a confiança institucional dos oficiais" e "aumentar a consciência de suas capacidades técnicas e organizacionais consideradas superiores à dos civis". (ROUQUIÉ, 1984, p. 175)

No plano político, o objetivo era fazer com que as forças militares nacionais encarassem seus problemas a partir da ótica norte-americana. O papel de defesa do status quo acentuou-se, na medida em que qualquer oposição aos EUA e aos governos locais afinados com os Estados Unidos passou a ser vista como impregnada de um caráter comunista. Intentava-se assim transformar os exércitos sul-americanos em "guardas nacionais", tal como o modelo desenvolvido pelo país na região da América Central e 
caribenha, colocando-as "afinadas às perspectivas estratégicas dos EUA e capazes de considerar os problemas nacionais sob o ângulo dos interesses do país líder do mundo livre". Rouquié, dessa forma, não discorda de Comblin quanto às intenções norteamericanas, mas diverge quanto à passividade das elites nacionais diante de tal cenário.

A busca pelo domínio não se deu somente no plano político e ideológico. Segundo Rouquié, a DSN é extremamente liberal na retórica, embora não o seja na prática, na medida em que teria sido acompanhada por procedimentos intervencionistas no plano econômico por parte dos governos militares ${ }^{12}$. No entanto, o autor se mostra contraditório quanto a essa questão, parecendo encaminhar na direção que aponta a plena associação entre liberalismo e Doutrina de Segurança Nacional:

Nessas economias permeáveis, em que as burguesias estão amplamente associadas com seus parceiros norte-americanos, é sem dúvida abusivo repetir, com o ex-presidente dominicano J Bosch, que o "pentagonismo é um substituto do imperialismo (ROUQUIÉ, 1984, p. 181)".

A segurança nacional coincidiria com as leis do capitalismo e com a nova dimensão do trabalho, sufocando-se a política para liberar a economia. A única verdadeira liberdade seria a de empreendimento econômico. O projeto econômico liberal se adequaria plenamente com a noção de "democracia protegida” chilena, lógica essa que também "não parece estranha ao regime pseudo-civil no Uruguai" (ROUQUIÉ, 1984, p. 315). No caso brasileiro, o modelo que acabou sendo imposto foi o da aplicação de um ultraliberalismo. Embora Rouquié afirme que as Forças Armadas não eram meros instrumentos nas mãos da burguesia, assinala que "são tributários da cultura política das classes dominantes internas ou externas, cujo liberalismo interessado constitui um limite para os élans orgânicos dos homens das casernas" (ROUQUIÉ, 1984, p. 407).

12 O intervencionismo teria sido maior no caso brasileiro, pequeno nos casos uruguaio e argentino e praticamente inexistente no Chile. Afirma que "a liberação da economia esbarrou não apenas no comportamento estatal dos quadros do Exército, mas também em seus interesses adquiridos, agravados pela colonização do Estado" (IDEM, p. 352). Em outro trecho, afirma que mesmo onde se observa o credo liberal e sua prática, "geralmente são acompanhados por um crescimento do setor nacionalizado" (IDEM. p. 348). A afirmação parece se estender para os quatro casos nacionais, onde Rouquié assinala que a DSN se instalou de forma efetiva, ainda que com variações. 
De outro lado, parte de uma argumentação que busca relativizar a influência da DSN, insistindo na ideia de que atribuir "'a orientação contrarrevolucionária maniqueísta unicamente à influência das doutrinas made in USA,se não decorre de um erro de perspectiva, pelo menos revela um exagero bastante grande" (ROUQUIÉ, 1984, p. 172). O treinamento nas escolas estadunidenses não teria "ressocializado" os militares latinos, principalmente nas Forças Armadas das grandes nações que eram mais profissionalizadas e menos dependentes. Além disso, a "ideologia contrarrevolucionária” foi geralmente elaborada de forma rústica, chegando a ser efetivamente uma doutrina de "'segurança nacional" somente em alguns casos, como no Brasil, o que pode ser estendido também aos países do Cone Sul.

Com a relativização da capacidade dessa doutrina militar de ter se disseminado dentre a oficialidade dos países do continente, Rouquié procura realçar as questões internas, bem como a trajetória das instituições na região. Efetivamente, para o autor, a Doutrina

\footnotetext{
"não foi imposta de fora, mas sim aceita, isto é, na maior parte dos países essa ideologia simplesmente criou seu próprio espaço. A colaboração militar dos Estados Unidos foi 'conscientemente buscada pelos Estados Maiores latino-americanos'(ROUQUIÉ, 1984, p. 174)”.
}

Valorizando assim os cenários nacionais, considera que, tanto a "mão do estrangeiro", quanto os "agentes revolucionários" somente alcançam seus objetivos “quando o terreno é propício. Avaliar o papel da DSN de outra forma tão somente contribuiria para a elaboração de uma "história-complô" marcada por preconceitos, uma vez que "as Forças Armadas do subcontinente não esperaram pelo Pentágono e as injunções de MacNamara ou de Kennedy para privilegiar o inimigo interior”. Dessa forma, seriam "os problemas internos, os perigos domésticos, sociais ou políticos que solicitam propriamente a ação militar das forças armadas latino-americanas (ROUQUIÉ, 1984, p. 123)". Mesmo o papel de interprete da nação e o messianismo já estariam presentes ao longo da modernização precoce que as Forças Armadas passam diante do restante das instituições estatais na América Latina. 
Apontando outro fator que relativiza os efeitos da Doutrina na região, para o autor, diferentemente do que consideram Comblin e Valdés, as ditaduras militares não teriam ideologia. A DSN forneceria tão somente um discurso que buscava mais dissimular a ilegitimidade em vez de criar uma nova legitimidade.Assim, "a teoria da segurança nacional não substitui absolutamente a ideologia, nem por sua consistência, nem por sua difusão, e nem mesmo por sua função constituinte" (ROUQUIÉ, p. 407). A ação contrarrevolucionária pode ter sido potencializada pela DSN, mas não dependeu única e exclusivamente dessa.

Tal como observável na perspectiva de Herrera, ainda que apontando elementos diversos, essa avaliação busca resgatar o protagonismo das Forças Armadas nacionais no desencadeamento dos golpes civil-militares. Afinal, se "Fort Gulick é a escola dos golpes de estado, as forças armadas do continente são muito simplesmente manipuladas pela metrópole" (ROUQUIÉ, 1984, p. 169). Ratificar a ideia de competência norte-americana quanto a sua intencionalidade significaria superdimensionar "o sucesso da política imperialista e negar as especificidades nacionais e individuais" (ROUQUIÉ, 1984, p. 170).Nesses países, conclui o autor, a DSN nada mais fez do que potencializar uma ideologia contrarrevolucionária.

Segundo Rouquié a chave para a compreensão do militarismo da segunda metade do século XX não está tão somente na DSN, mas sim no conhecimento da própria estrutura e formação das Forças Armadas da região. Aspectos que contribuíram para esse militarismo seriam: o papel de controle interno que foi cada vez mais designado aos militares; o seu isolamento, dado por sua formação técnica com o processo de modernização; a inexistência de conflitos internos que contribuíam para a crescente politização e sua compreensão de que a eles caberia um papel estabilizador.

\section{Considerações Finais}

Busquei apresentar quatro das primeiras perspectivas sobre a Doutrina de Segurança Nacional e seus reflexos na América Latina. Elaboradas em 1979 (Comblin), 1980 (Valdés), 1981 (Herrera) e 1982 (Rouquié) as obras, exceção ao trabalho de Comblin 
- o primeiro deles -, dialogam diretamente entre si. Observa-se a relevância das mesmas pela incorporação que boa parte da historiografia faz de diversos elementos presentes nas perspectivas desses autores. De forma resumida, apresento agora os principais pontos de controvérsia entre essas análises.

Comblin e Valdés caracterizam os elementos centrais que compunham a Doutrina, seus conceitos e os suportes (visões de mundo) de tais perspectivas que marcaram esse conjunto de ideias" ${ }^{13}$. Valdés é o único a caracterizar a DSN como um "fascismo dependente". Comblin, Herrera e Rouquié se distanciam dessa perspectiva, embora apontem a existência de elementos fascistas nas ditaduras implementadas com base na Segurança Nacional. A obra do primeiro, ainda que publicada anteriormente ao trabalho de Valdés faz críticas a essa associação: “É preciso não esquecer os traços específicos do fenômeno latino-americano" (COMBLIN, 1979., p. 91). Rouquié contesta o rótulo de regime fascista ou totalitário, uma vez que são "regimes sem partido único", não tem “uma base de massa" e, diferentemente, “despolitizam os cidadãos", incitando-os "a voltar para a vida privada" (ROUQUIÉ, 1984, p. 316).

Herrera foi o primeiro autor a relativizar a ideia apresentada por Comblin e Valdés de que, tanto a geopolítica quanto o anticomunismo, teriam sido difundidos a partir da DSN propagada pelos Estados Unidos. Para o autor, o aparecimento de ambos foi anterior, com o anticomunismo propagando-se no meio militar a partir das missões militares estrangeiras. Já a geopolítica, embora também surja com as missões militares estrangeiras teve uma aceitação limitada em princípios do século, o que teria se modificado tão somente a partir dos anos 40. Nesse sentido, a matriz ainda não era a norte-americana. Rouquié segue a perspectiva de Herrera de que o anticomunismo foi difundido pelas missões estrangeiras contratadas para o processo de modernização das Forças Armadas latino-americanas. Mas entende que o desprezo pelos civis e pelo processo político é anterior, com sua origem no século XIX.

\footnotetext{
${ }^{13}$ Uma série de estudos recentes vão na direção de destacar a importância da análise da Doutrina de Segurança Nacional para a compreensão das ditaduras civil-militares. Dentre esses destaco: TCHACH (2006), ZARÁTE (2003), PADRÓS (2004), BORGES (2003), NAVARRO e PALERMO (2004) dentre outros.
} 
Outro fator de divergência dentre os autores analisados nesse artigo refere-se à discussão sobre a origem da Doutrina. Segundo Valdés e Rouquié, foi a partir exclusivamente dos Estados Unidos que a DSN se originou e se difundiu. Valdés vê a DSN como uma obra efetiva do imperialismo estadunidense. Rouquié, ainda que relativize o papel da Doutrina na consecução dos regimes militares, entende também que sua origem é obra norte-americana. Comblin, por sua vez, chega a fazer referência ao papel francês nesse processo, porém atribuiu uma importância menor a isso. De outro lado, Herrera atribui uma grande importância a essa matriz francesa no que se refere noção de guerra contra-subversiva, bem como quanto aos procedimentos de sua implementação. Considera que, nos Estados Unidos e naFrança, “ 'la respuesta flexible’ norteamericana y la 'estratégia de la acción' del general Beaufre - apuntaban a conclusiones similiares" (HERRERA, 1986, p. 189) ${ }^{14}$.

O desprezo pela matriz francesa parece estar relacionado com a concepção que entrelaça a DSN à consolidação do liberalismo, o que atenderia aos anseios de hegemonia continental norte-americana. Comblin e Rouquié, embora relativizem a implementação do liberalismo pelas ditaduras civil-militares, acabam por apresentá-lo como um de seus objetivos. Os dois, ainda que em determinados momentos refutem isso - apontando o grau de presença do Estado nessas ditaduras -, estabelecem ao final que os militares seriam instrumento da burguesia multinacional associada e seus intermediários nacionais. Rouquié, talvez, se afaste um pouco dessa avaliação na medida em que, enfatiza mais que os outros, que a Doutrina visava, antes de tudo, a manutenção do status quo e o combate à subversão, ou seja, estava associada a uma defesa mais ampla do capitalismo, independentemente de ser liberal, ou intervencionista ${ }^{15}$.

Por último, importa assinalar duas questões presentes nessas obras e que contribuem para a identificação do real protagonismo no desencadeamento dos “golpes". Primeiro, que a difusão da DSN, em países como Brasil, Chile, Argentina e

\footnotetext{
${ }^{14}$ Trabalhos recentes que sinalizam na valorização do papel francês tanto na estruturação de parte da Doutrina quanto na sua divulgação foram elaborados por Ferraz (1997), Coggiola (2001),Martins Filho (2004), Santucho (2005), Tcach (2006) e Araujo (2008).

${ }^{15}$ Autores como ZÁRATE (2006) e FONTANA (1984) avaliam elementos desse intervencionismo ao longo das ditaduras civil-militares.
} 
Uruguai,aconteceu de forma ampliada, extrapolando os muros da caserna por iniciativas de civis que partilhavam desses valores. Valdés e Herrera são os autores que mais sinalizam nessa direção. Valdés chega a comentar, inclusive, que a difusão da DSN entre os civis foi anterior à desenvolvida pelos os militares no caso chileno ${ }^{16}$. O resgate desses aspectos contribui para destacar o entrelaçamento das elites civis no desenvolvimento das ditaduras fundadas na Doutrina de Segurança Nacional.

O segundo elemento apresenta-se como desdobramento do anterior. Ainda que oriunda de fora, a DSN foi difundida por militares e civis - argentinos, chilenos, brasileiros e uruguaios -, não porque tenham sido manipulados por forças externas. Como muito bem assinala Rouquié, a “colaboração militar dos Estados Unidos foi conscientemente buscada pelos Estados Maiores latino-americanos" (ROUQUIÉ, 1984, p. 174). Poderíamos completar acrescentando ainda, buscado também avidamente pelas elites da sociedade política e da sociedade civil.

\section{Referências}

BORGES, Nilson. A Doutrina de Segurança Nacional e os governos militares. In: FERREIRA, Jorge; DELGADO, Lucilia de A. Neves. O Brasil republicano: o tempo das ditaduras. Rio de Janeiro: Civilização Brasileira, 2003, p.13-43

COGGIOLA, Osvaldo. Governos militares na América Latina. São Paulo: Contexto, 2001

COMBLIN, Joseph. Ideología de segurança nacional. Rio de Janeiro: Paz e Terra, 1979.

FICO, Carlos. Espionagem, polícia política, censura e propaganda: os pilares básicos da repressão. In: FERREIRA, Jorge; DELGADO, Lucilia de Almeida Neves. O Brasil Republican: o tempo da ditadura. Rio de Janeiro: Civilização Brasileira, 2003, p.167-206.

FONTANA, Andrés. Forças Armadas e ideologia neoconservadora: o encolhimento do Estado na Argentina (1976-1981). Dados - Revista de ciências sociais, Rio de Janeiro: v. 27, n. 3, p.347-359.1984

LINK, Arthur S. História Moderna dos Estados Unidos. Rio de Janeiro, Zahar, 1965

\footnotetext{
${ }^{16}$ Artigo de Mendes (2005) assinala que no Brasil a difusão da DSN dentre civis vinculados ao IPÊS e de parlamentares da UDN foi intensa.
} 
HERRERA, Genaro A. El pensamiento político de los militares. Santiago: Centro de Investigaciones Socioeconómicas, 1986. $6^{\text {a }}$. Edição

MARTINS FILHO, João Roberto. A educação dos golpistas: cultura militar, influência francesa e golpe de 1964, 2004. (mimeo)

MENDES, Ricardo Antonio Souza . Visões das direitas no Brasil (1964-1965). Tese (doutorado). Universidade Federal Fluminense, Doutorado em História Moderna e Contemporânea Niteroi, 2003.

MENDES, Ricardo Antonio Souza. Cultura e repressão nos tempos do Al-5. In: MUNTEAL FILHO; FREIXO, Adriano de; FREITAS, Jacqueline Ventapane. (Orgs.). Tempo negro, temperatura sufocante: estado e sociedade no Brasil do Al-5. Rio de Janeiro: Ed. PUC-Rio; Editora Contraponto, 2005, p. 259-288

MORAES, Maria Lygia Quartin de. O golpe de 1964: testemunho de uma geração. In: REIS, Daniel Aarão; RIDENTI, Marcelo; SÁ MOTTA, Rodrigo Patto. O golpe e a ditadura militar: quarenta anos depois (1964-2004). Bauru: Edusc, 2004, p. 297-314.

NAVARRO, Marcos; PALERMO, Vicente (Comp.). História Argentina: la dictadura militar - 19761983. Del golpe de Estado a la restauración democrática. Buenos Aires: Paidós, 2003.

OLIVEIRA, Eliezer Rizzo. As Forças Armadas: política, e ideologia no Brasil (1964-1969). Petrópolis: Vozes, 1976.

PADRÓS, Enrique Serra; MARÇAL, Fábio Azambuja. Terror de Estado e Doutrina de Segurança Nacional: os anos de chumbo no Brasil e na América Latina. Revista Ciências \& Letras., Porto Alegre: FAPA, n.. 28, p. 55-90. 2000

PADRÓS, Enrique Serra; MARÇAL, Fábio Azambuja. A ditadura civil-militar no Uruguai (1973-1984). In; WASSERMAN, Claudia; GUAZZELLI, Cesar Augusto Barcellos (Org). Ditaduras Militares na América Latina. Porto Alegre: Editara da UFRGS, 2004, p. 45-78.

ROMERO, LuisAlberto. Breve historia contemporánea de la Argentina. Buenos Aires: EFE, 2004, $2^{\mathrm{a}}$ ed.

ROUQUIÉ, Alain. O Estado Militar na América Latina. Rio de Janeiro: , Alfa-Ômega, 1984.

SANTUCHO, Hugo. Los últimos de los guevaristas: la guerrilla marxista en la Argentina.Buenos Aires: Ediciones B. Argentina, 2005.

SKIDMORE, Thomas. Brasil: de Castelo a Tancredo. Rio de Janeiro: Paz e Terra, 1988.

SURIANO, Juan. Introducion: una Argentina diferente. In: SURIANO, Juan. (Org.).Nueva historia Argentina. Buenos Aires: Editorial Sudamericana, 2005, p. 11-33

TCACH, César. Entre la lógica del partisano y el império del Gólem: dictadores y guerrilleros en Argentina, Brasil, Chile y Uruguay. In: QUIROGA, Hugo; TCACH, César. Argentina 1976-2006. Buenos Aires: Universidad Nacional del Litoral \& Homo Sapiens Ediciones, 2006. p. 123-166 
VALDÉS, Jorge Alberto Tapia. El terrorismo de Estado: la doctrina de la seguridad nacional en el Cono Sur. México (DF): Ediorial Nueva Imagen, 1980

YOCELEVZKY RETAMAL, Ricardo. Chile: partidos politicos, democracia y dictadura 1970-1990. Mexico (DF): Fondo de Cultura Económica, 2002.

ZARATE, Veronica V O. El golpe despues del golpe: Leigh vs Pinochet. Santiago: Lom, 2003.

Recebido em: 04/09/2013 Aprovado em: 20/11/2013

Universidade do Estado de Santa Catarina - UDESC

Programa de Pós-Graduação em História - PPGH

Revista Tempo e Argumento Volume 05 - Número 10 - Ano 2013 tempoeargumento@gmail.com 